\title{
Mobbing as an Organizational Phenomenon Impeding Implementation of Changes
}

\author{
Safina D. \\ Podgornaya A.
}

Kazan (Volga region) Federal University, 18, Kremlyovskaya Street, Kazan, Repablic of Tatarstan, Russian Federation, 420008

\section{Doi:10.5901/mjss.2014.v5n18p187}

\section{Abstract}

Most of organizations in Russia are not ready to be changed in compliance with the requirements being dictated by outside environment. The relevance of the study is stipulated by the requirement for detection of causes impeding timely implementation of changes. The figures stated in the article are based on the inquiry held among working undergraduates in higher training of Kazan Federal University, participants in a course of Presidential Retraining Program for managerial staff, responsible executives and workforce of the enterprises in the Republic of Tatarstan. The present article makes an attempt to investigate the main forms and types of mobbing specific to Russia as well as its causes and consequences. Since mobbing has an adverse impact on implementing organizational reassignment the authors consider ways out of the situation of systematical moral persecution.

Keywords: mobbing, bullying, bossing, organization, organizational changes.

\section{Introduction}

Every day most of the people face the problem of oppression at work. Mobbing is moral and sometimes even physical persecution at the workplace, i.e. harassment, pressing, «psychological terror», «human hunting». The word «mobbing» comes from the verb to mob- being attacked by a crowd. But you can be oppressed by either a group of people or by an individual person, and such being the case, this phenomenon is called bullying $[1,7]$. In such instance when the originator of aggression (mobber) is a senior executive, this effect being called bossing.

According to figures from the opinion poll at least one in every 20 working Russians fell a victim of mobbing.

The first studies in this field were carried out by Heinz Leymann in Sweden of the early 1980-s. Leymann defined mobbing as follows: «Mobbing means harassing, ganging up on someone, or psychologically terrorizing others at work. This is a persistent hostile and unethical attitude on the part of one individual or several persons directed towards others, primarily, Mr. Somebody or other, i.e a certain person ...» [1]. Further Leymann describes forty five behavioral patterns typical for mobbing [2].

Nowadays this phenomenon is highlighted all over the world. The fact that it is assigned a high priority is confirmed by many European countries having adopted a law of moral persecution at the workplace. Both mobbing and bullying are mentioned among such crimes as murder, forceful rape and robbery. Many countries are already counting losses from mobbing, thus, according to experts' estimates mobbing costs Germany economy 50 million euro a year. We have no similar estimates in our country apart from some mentions about the influence of non-economic factors $[8,9,10,11]$.

In Russia as a whole the studies devoted to the problem of persecution at the workplace are quite a rare thing. As usual such studies are carried out by sociologists who consider mobbing to be rather social phenomenon but not institutional and management problem. It should also be stated that the Russian legislation does not comprise a special law of moral persecution apart from article 151 in the Civil Code designated as «Compensation for moral injury». The citizens of the Russian Federation are practically defenseless in case of mobbing as far as it is often quite difficult to find witnesses of such actions and ram an argument home.

The objective of the given article to persuade the reader that the problem of mobbing is important today and show which forms and types of it he might face in the process of his labour activity. It is also important to reveal causes and consequences of mobbing, to expose its adverse impact on implementing organizational reassignment and consider ways out of the situation of consistent moral persecution. 


\section{Method}

To write the given article the authors conducted a questionnaire of 315 respondents including working undergraduates in higher training of Kazan Federal University, participants in a course of Presidential Retraining Program for managerial staff, responsible executives and workforce of the enterprises in the Republic of Tatarstan.

\section{Result}

The first question put to the respondents stated: «How often do you feel adverse psychological state at work?» Most of the pollees (71\%) answered «sometimes», 11\% «never» and 18\% -«often». Obviously intermittent adverse psychological state occurs due to the phenomenon of mobbing. Indeed, as it turned out $93 \%$ of female and $85 \%$ of male faced the problem in one form or another.

Further the authors investigated which forms of mobbing most often faced our respondents in their professional experience.

Table 1. Most common forms of mobbing.

\begin{tabular}{|c|l|c|}
\hline \multicolumn{2}{|l|}{ Which forms of mobbing did you encounter within your working practice? } & $46 \%$ \\
\hline 1 & I am overloaded with work being outside my duties; & $24 \%$ \\
\hline 2 & I am given not challenging tasks (being not of high-profile); & $20 \%$ \\
\hline 3 & $\begin{array}{l}\text { Co-workers generate an atmosphere of informational vacuum for me : all necessary information is } \\
\text { concealed or submitted too late }\end{array}$ & $20 \%$ \\
\hline 4 & I am put on a charge of mistakes either made by the others or I have never made at all; & $17 \%$ \\
\hline 5 & I am unreasonably criticized; & $11 \%$ \\
\hline 6 & I am scoffed at; & $11 \%$ \\
\hline 7 & I am not invited to operational meetings and workshops; & $11 \%$ \\
\hline 8 & My contribution to the common cause is out of attention, my progress is ignored; & $11 \%$ \\
\hline 9 & My ideas and proposals are ignored; & $11 \%$ \\
\hline 10 & I am not crowded at fulfilling my assignment; & $7 \%$ \\
\hline 11 & They intentionally focus people's attention on my faults and misses; & $6 \%$ \\
\hline 12 & $\begin{array}{l}\text { physical actions (move my workplace, displace my papers on the table, lose my documents, pour out } \\
\text { coffee on the documents, put out of action my PC, Xerox, etc., delete important files and other); }\end{array}$ & $6 \%$ \\
\hline 13 & My opinion is out of interest for everyone; & $6 \%$ \\
\hline 14 & I am moved sideways, not upgraded; & $6 \%$ \\
\hline 15 & $\begin{array}{l}\text { Other (the respondents themselves filled this line): chief's arrogance, periodic hinting at my being } \\
\text { employed with external assistance; brushing aside my requests; }\end{array}$ & $4 \%$ \\
\hline 16 & Co-workers take no notice of my presence; & $4 \%$ \\
\hline 17 & Co-workers stab in my back and spread rumours; & $4 \%$ \\
\hline 18 & $\begin{array}{l}\text { I am assaulted, given redirections and nasty remarks (comments of my vocational maladjustment, } \\
\text { appearance and so on) }\end{array}$ & $4 \%$ \\
\hline 19 & I am never encouraged, always de-bonused and never praised in public; & $2 \%$ \\
\hline 20 & I am often called by a nick-name; & $2 \%$ \\
\hline 21 & I often face silent treatment; & $0 \%$ \\
\hline 22 & physical abuse (fights, flaps in the face, etc.) & $0 \%$ \\
\hline 23 & I am not invited to any corporate events outside of working hours; & $0 \%$ \\
\hline 24 & $\begin{array}{l}\text { Co-workers declare a boycott, spread rumours and report the executive officials on me with the result } \\
\text { that the latter stop encharging me with tasks and assignments; }\end{array}$ \\
\hline 25 & Actions directed against me and qualified as sexual harassment; & $0 \%$ \\
\hline
\end{tabular}

The polling data prove that the most typical forms of mobbing appear to be: the requirement to do the work being outside one's duties: $46 \%$ pollees were in favour of it; giving not challenging tasks (being hopeless or not of high-profile); generating an informational vacuum when all necessary information is concealed or submitted too late - 20\%; putting on a charge of mistakes either made by the others or never made at all - 20\%; unreasonable and unfair criticism of the «victim»- 7\%.

Onward the authors studied which forms of mobbing the respondents most often encountered in their working practice. It turned out to be obvious that the most typical is so called lateral mobbing (48\%), i.e. on the part of colleagues 
expressed both in a hidden latent form (33\%) and in an apparent form (15\%).

Another typical phenomenon is upright mobbing- (45\%) i.e. pressing on the part of higher management and also being in a hidden form - (26\%) and in an apparent form - (19\%). It is noteworthy to mention that the authors itemized separately institutional mobbing having been experienced by $9 \%$ of respondents. To put institutional mobbing into practice such patterns as certification of personnel, qualification examinations, etc.

Table 2. Who initiated mobbing in your organization?

\begin{tabular}{|c|l|c|}
\hline 1 & direct supervisor; & $33 \%$ \\
\hline 2 & a colleague; & $30 \%$ \\
\hline 3 & co-workers;. & $22 \%$ \\
\hline 4 & Chief (director); & $15 \%$ \\
\hline 5 & I was the initiator of mobbing; & $4 \%$ \\
\hline
\end{tabular}

What's curious is that only $4 \%$ of the pollees avowed themselves as an aggressor, one of them being a company director himself.

Table 3. Mobber's goals.

\begin{tabular}{|c|l|c|}
\hline & $\begin{array}{l}\text { How do you think, for what purpose people begin envenom life of their colleagues or subordinates in your } \\
\text { organization? }\end{array}$ & $48 \%$ \\
\hline 1 & $\begin{array}{l}\text { to bolster self-esteem at somebody else's expense - humiliating others brings pleasure, a mobber feels } \\
\text { all - powerful due to his impunity; }\end{array}$ & $33 \%$ \\
\hline 2 & to get abreaction from emotional stress by way of attacking against other person; & $28 \%$ \\
\hline 3 & to test a fresher to «destruction»; & $28 \%$ \\
\hline 4 & to gain power, authority, status, respect; & $20 \%$ \\
\hline 5 & with a view to drive out a «victim» of a company; & $19 \%$ \\
\hline 6 & to progress up the career ladder; & $17 \%$ \\
\hline 7 & to intimidate a person and put the part of work on him; & $4 \%$ \\
\hline 8 & $\begin{array}{l}\text { managers do it intentionally to make organization undesirables resign voluntarily with the aim not to pay } \\
\text { them a dismissal wage; }\end{array}$ & $4 \%$ \\
\hline 9 & $\begin{array}{l}\text { other: people are not responsible for their doings, they cause inconvenience and pain to others without a } \\
\text { moment's hesitation; a mobber is afraid that his/her mistakes will be apparent that's why he/she attacks } \\
\text { first under the principle of "attack is the best form of defense " }\end{array}$ \\
\hline
\end{tabular}

As it is seen from the table, in the respondents opinion most often the mobber's goal is to to bolster self-esteem at the victim's expense and feel all - powerful - (48\%), to get abreaction from emotional stress by way of attacking against other person- 33\%; to test a fresher to «destruction» - 28\%; to gain power, authority, status, respect - 28\%; with the purpose to drive out a «victim» of a company - 20\%; to progress up the career ladder - $19 \%$.

It should be noted that overwhelming majority of students participated in the poll outlined as the mobber's goal the line «to test a fresher to «destruction» as far as most of them learnt it to own cost.

Table 4. The most commonly encountered causes of mobbing in an organization

\begin{tabular}{|c|l|c|}
\hline & How do you think, what can cause mobbing in your organization? & $35 \%$ \\
\hline 1 & outburst of adverse emotions connected with personal problems; & $33 \%$ \\
\hline 2 & $\begin{array}{l}\text { individual psychological constitution of people, presence of certain type of persons being intriguers and lovers of } \\
\text { behind-the-scenes games; }\end{array}$ & $31 \%$ \\
\hline 3 & $\begin{array}{l}\text { other person's success on whose background «aggressor» feels as unlucky fellow and making the «lucky } \\
\text { strike's» life miserable he goes up in his estimation; }\end{array}$ & $24 \%$ \\
\hline 4 & some people are extremely ambitious and arrogant treating those around them with conscious superiority; & $22 \%$ \\
\hline 5 & a colleague who lays down his own rules alleging as his reason that he knows everything better than others; & $22 \%$ \\
\hline 6 & low cultural level of co-workers, clownish behaviour in organization, non- compliance with the norms of ethic & $20 \%$ \\
\hline 7 & $\begin{array}{l}\text { Unfriendly atmosphere in organization: when falling among evil companions even positive and friendly people } \\
\text { turn out to be amenable and surrender to «herd instinct»; }\end{array}$ & $20 \%$ \\
\hline 8 & a person in charge himself provokes mobbing: knocks people together, encourages competitive struggle for & 20 \\
\hline
\end{tabular}


professional advancement, listens to the gossips and reports on colleagues, promotes intriguing, threatens with resignation, makes subordinates write letters of explanation at the slightest pretext or encourages some employees' caddish behavior, etc. [3];

9 Envy of youth, beauty, wit, wealth and talent and so on;

10 not sharply defined boundary of responsibilities and professional duties;

11 labour misarrangement and consequently severe overload of some co-workers;

12 a person in charge needs to clear a space for advancement of «a cater-cousin»;

$5 \%$

Mobbing is engendered by a lot of causes and can be connected with individual psychological constitution of a person such as behavior, emotions (envy and fear) as well as organizational problems.

Among the organizational problems we cannot but mention: not sharply defined limits of responsibilities and professional duties, unfair system of labour remuneration, corporate culture making possible loyalty to maneuvers and communication upon bad terms within a company.

Mobbing can emerge in view of adverse situation a person turned out to be. For instance, when two co-workers being candidates for one and the same position or when a person in charge himself tries to eliminate possible competitors buy way of mobbing. In our opinion, there is always a cause but though rarely, the pollees respond: «No cause, «he simply drives everyone nuts, that's all!» - (6\%)

Among most common causes the respondents outline: outburst of adverse emotions connected with personal problems - (35\%); individual psychological peculiarities of people, presence of certain type of persons being intriguers and lovers of behind-the-scenes games - 33\%; other person's success on whose background «aggressor» feels as unlucky fellow and making the «lucky strike's» life miserable he goes up in his estimation - 31\%; some people are extremely ambitious and arrogant treating those around them with conscious superiority - 24\%; a colleague who lays down his own rules alleging as his reason that he knows everything better than others - 22\%; low cultural level of coworkers, caddish behaviour in organization, non- compliance with the norms of ethic - $22 \%$.

Most of men consider the cause of mobbing to be commission or omission of actions but the majority of women find it to be envy and fear.

Table 5. Potential adverse effects of mobbing for people.

\begin{tabular}{|c|l|c|}
\hline & Have you ever experienced the following consequences of mobbing? & \\
\hline 1 & Stress; & $46 \%$ \\
\hline 2 & disturbance of the general sense of well-being, headaches; & $35 \%$ \\
\hline 3 & feeling of guilt, doubt and shame; & $28 \%$ \\
\hline 4 & the state of apathy, loss of interest in labour and depression; & $28 \%$ \\
\hline 5 & had to quit the job; & $17 \%$ \\
\hline 6 & nervousness, paranoia; & $6 \%$ \\
\hline 7 & loss of wages; & $6 \%$ \\
\hline 8 & \begin{tabular}{l} 
something other: the feeling of helplessness due to awareness of impossibility to wreak \\
\hline 9
\end{tabular} & vengeance upon aggressor; loss of wish to self-actualize; self estimate lowering \\
\hline 10 & failed to make a career for himself/herself; & $4 \%$ \\
\hline 11 & diseases (stomach ulcer, chronic insomnia, absent-mindedness, heart attack, etc.) & $4 \%$ \\
\hline 12 & indulge in stimulants (alcohol, tobacco, medicines); & $4 \%$ \\
\hline 13 & thinking of suicide; & $0 \%$ \\
\hline
\end{tabular}

Among the most common reactions to pressing the respondents underlined stress - 46\%; disturbance of the general sense of well-being, headaches - 35\%; feeling of guilt, doubt and shame - 28\%; the state of apathy, loss of interest in labour and depression - 28\%; had to quit the job - $17 \%$.

Thus, day-to-day the victims of mobbing live in condition of the strongest stress, mobbing bringing about psychological and physical exhaustion. Moreover, a person underestimates himself /herself and begins to mistrust own powers and professional abilities. If it is remembered that we spend at work a third of our life, quality of living being significantly deteriorated. Enhanced psychological terror can give a heart attack and finally force a person to commit suicide $[4,13]$.

In the long run, it is not only an employee who suffers from mobbing but the organization in whole. A large amount of energy and time is spent for «struggle», workforce productivity being lowered. People make mistakes which can bring 
about loss of clients while everlasting maneuvers and mobbing destroy confidence and dent the company's reputation. Co-workers can disseminate confidential information about the company in order to take vengeance on the chief. The company can lose key employees $[5,12]$.

The respondents were asked about mobbing influence over reassignment changes. Seventy five per cent (75\%) reckon that the phenomenon of mobbing impedes introducing any organizational changes. Twenty five per cent (25\%) of respondents esteem that efficacious implementation of changes does not depend on the atmosphere in the organization and relations inside the team.

According to Klaus Niedl «Employees do not cope with mobbing by using simple flight or fight reactions (e.g. absenteeism, lower level of productivity). The results suggest that it should be possible to identify mobbing in an early stage, which, in turn, should enhance the prevention of mobbing» $[6,14]$. We also decided to find out which way out of persistent moral persecution our respondents see. The pollees were offered 11 variants of this problem solution, the results are given in table 6 .

Table 6. Ways of solving the problem of persistent moral persecution at workplace.

\begin{tabular}{|l|l|c|}
\hline 1 & $\begin{array}{l}\text { to raise professional level up to the bar in order to become «untouchable», impossible to be replaced, prove own } \\
\text { profitableness for the organization, chief, colleagues; }\end{array}$ & $50 \%$ \\
\hline 2 & to reject the imposed role of a victim, be confident, keep balance of mind and not to be associated with oppression & $37 \%$ \\
\hline 3 & to treat everything with a sense of humour and thus pass through the hard period & $30 \%$ \\
\hline 4 & $\begin{array}{l}\text { to find out why they hate you so much and change your behavioral pattern (for instance, stop boasting not to be } \\
\text { envied; to adapt for a mobber, not to establish your own rules; something other) }\end{array}$ & $22 \%$ \\
\hline 5 & to respond the aggressor with the same, i.e. aggressive actions; & $20 \%$ \\
\hline 6 & to quit the job; & $17 \%$ \\
\hline 7 & to report higher management on colleagues; & $7 \%$ \\
\hline 8 & to exchange into another subdivision; & $6 \%$ \\
\hline 9 & to do nothing, just bear since «the way things are »; & $2 \%$ \\
\hline 10 & to file a lawsuit in court seeking compensation for moral harm; & $0 \%$ \\
\hline 11 & to apply to labour union(if any); & $0 \%$ \\
\hline
\end{tabular}

The ways of solving the problem of persistent moral persecution at workplace depend on the causes having given rise to the situation. Most of the respondents (50\%) see a way out in raising their professional level up to the bar in order to become «untouchable», impossible to be replaced, prove own profitableness for the organization, chief and colleagues. Furthermore, it is necessary to refuse from the imposed role of a victim, be confident, keep balance of mind and not to be associated with oppression - (37\%). Some people believe that to treat everything with a sense of humour and thus pass through the hard period is the best way - 30\%. The others consider that you need find out why they hate you so much and change your behavioral pattern (for instance, stop boasting not to be envied; to adapt for a mobber, not to establish your own rules; something other) - $22 \%$. Most of men being asked are sure that it is necessary to respond the aggressor with the same, i.e. aggressive actions $-20 \%$.

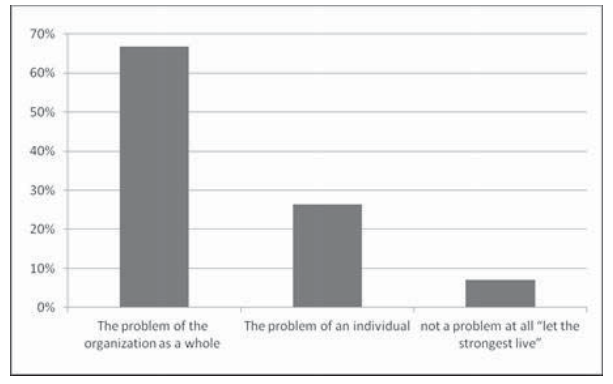

Figure.1 Mobbing: whose problem is this?

To complete the studies we decided to get an answer to the question: whose problem could be mobbing? According to respondents this problem relates to the organization as a whole - 67\%; the problem of an individual - 26\%; not a problem at all "let the strongest live" - 7\%. 


\section{Conclusion}

As can be seen from the above most of the respondents (67\%) consider mobbing to be the problem of the organization as a whole. In our opinion as far as people stay on their own with mobbing and moreover, mobbing will stay a part of organizational culture and the style of management, we'll never find the solution. Organization systems characterized by the culture of suppression are not susceptible to changes in them and make people be inert. To solve the problem we need joint efforts of management and staff where the first step to recognize its availability.

\section{References}

Heinz Leymann (1996) The content and development of mobbing at work, European Journal of Work and Organizational Psychology, p. 165-184

Shaidullin R.N., Ulesov D.V., Shigabieva A.M. and Safiullin L.N. Innovative Infrastructure in Post-Industrial Society// World Applied Sciences Journal, 27(13), 2013, pp. 180-183.

Panasyuk, M.V., Safiullin, L.N., Pryadko, I.A., Anopchenko, T.Y. Classification of large and socially important enterprises of the region by the levels of their economic solvency // World Applied Sciences Journal, 27(13), 2013, 140-144.

Safiullin, M.R., Elshin, L.A., Prygunova, M.I., Galyavov, A.A. (2013). Complex Analysis of Prospects of the Volga Federal District Regions Development: Methodology and Practice. World Applied Sciences Journal 27, 4, 508-511.

Robert Bruce Shaw (1997) Trust in the balance, building successful organizations on results, integrity, and concern, Jossey-Bass Publishers, p. 242

Christa Kolodej (2005) Mobbing, Psychoterror am Arbeitsplatz und seine Bewältigung, Facultas Verlags- and Buchhandels AG, p.368

Dieter Zapf, (1999) "Organisational, work group related and personal causes of mobbing/bullying at work", International Journal of Manpower, Vol. 20 Iss: 1/2, pp.70 - 85

Safiullin, M.R., Elstin, L.A., Shakirova, A.I. 2012. Evaluation of business and economic activity as a short-term forecasting tool // Herald of the Russian Academy of Sciences (4) , pp. 290-294.

Kirshin I.A., Datsyk A.A., Titov A.V.(2013) Forecasting the Dynamics of an Innovative Cycle. World Applied Sciences Journal 27 (Economics, Management and Finance) P. 197-201

Averianov, B.A., Bagautdinova, N.G., Sarkin, A.V. Estimation of manufacturing enterprise development risks in process of operational activity // World Applied Sciences Journal, 27(13), 2013, 202-206.

Sarkin, A.V., Bagautdinova, N.G., Fazlieva, E.P., Averianov, B.A. Development and implementation of machinery building enterprises complex development strategies in the contexts of the contemporary Russian economy institutes // World Applied Sciences Journal, 27(13), 2013, 174-179.

Ulesov D.V., Shigabieva A.M., Maratkanova E.M. and Shaidullin R.N. Information Infrastructure of Small Business Development// World Applied Sciences Journal, 27(13), 2013, pp. 193-196.

Klaus Niedl (1996) Mobbing and well-being: Economic and personnel development implications European Journal of Work and Organizational Psychology,Volume 5, Issue 2, pp. 239-249

Bryant M., Buttigieg D., Hanley G. Poor bullying prevention and employee health: some implications. // International Journal of Workplace Health Management, 2009. Vol. 2. Iss: 1. P. 48 - 62. 